\title{
Preliminary study of the Gravimetric Local Geoid Model in Jordan: case study (GeoJordan Model)
}

\author{
Omar Al-Bayari and Abdallah Al-Zoubi \\ Department of Surveying and Geomatics Engineering, Faculty of Engineering, \\ Al-Balqa' Applied University, Al-Salt, Jordan
}

\begin{abstract}
Recently, there has been an increased interest in studying and defining the Local and Regional Geoid Model worldwide, due to its importance in geodetic and geophysics applications. The use of the Global Positioning System (GPS) is internationally growing, yet the lack of a Geoid Model for Jordan has limited the use of GPS for the geodetic applications in the country. This work aims to present the preliminary results that we propose for «The Gravimetric Jordanian Geoid Model (GeoJordan)». The model is created using gravimetric data and the GRAVSOFT program. The model is validated using GPS and precise level measurements in the Amman area. Moreover, we present a comparison using the Global Geopotential Model OSU91A and the EGM96 Model and the results showed great discrepancies. We also present the approach used to obtain the orthometric height from GPS ellipsoidal height measurements. We found that the error margin obtained in this work of the GeoJordan after fitting the data with GPS/leveling measurements is about $(10 \mathrm{~cm})$ in the tested area whereas the standard error of the created model is about $(40 \mathrm{~cm})$.
\end{abstract}

Key words Gravimetric Jordanian Geoid Model (GeoJordan) - Least Square Collocation (LSC) Global Geopotential Model (GGM) - Global Positioning System (GPS) - undulation (N)

\section{Introduction}

The height obtained using GPS satellitebased-system is referred to the ellipsoid. Many engineering and geodetic applications are interested in the orthometric height, which is the height above the geoid, not above the ellipsoid (Featherstone et al., 1998). Thus the transformation between the two heights could be obtained directly knowing the geoid undulations (Marti,

Mailing address: Dr. Omar Al-Bayari, Department of Surveying and Geomatics Engineering., Faculty of Engineering, Al-Balqa' Applied University, Al-Salt 19117, Jordan; e-mail: obayari@bau.edu.jo
2002; Fotopoulos, 2003). Therefore, it became indispensable to define the geoid undulation in Jordan to allow more usage and benefit of GPS in the area. Furthermore, the determination of the Geoid Model for Jordan never was easy due to: the high costs of the process, difficulty accessing the gravimetric data that covers the country, difficulty to have GPS and precise leveling for the country to end with, the lack of access to the gravimetric data in the neighboring countries.

On the other hand, we used available gravimetric data collected by the Natural Resources Authority of Jordan (NRAJ) for geophysical purposes (Al-Zoubi, 2002). The number of gravimetric points measured offered a possibility to start creating a Geoid Model for Jordan. To validate the Gravimetric Geoid Model, GPS and precise leveling measurements were performed by the authors (at the Surveying and Geomatics Engineering department/Al-Balqa' Applied University) over a small area. The SRTM Digital Elevation Model (DEM) was used for the reduction of 


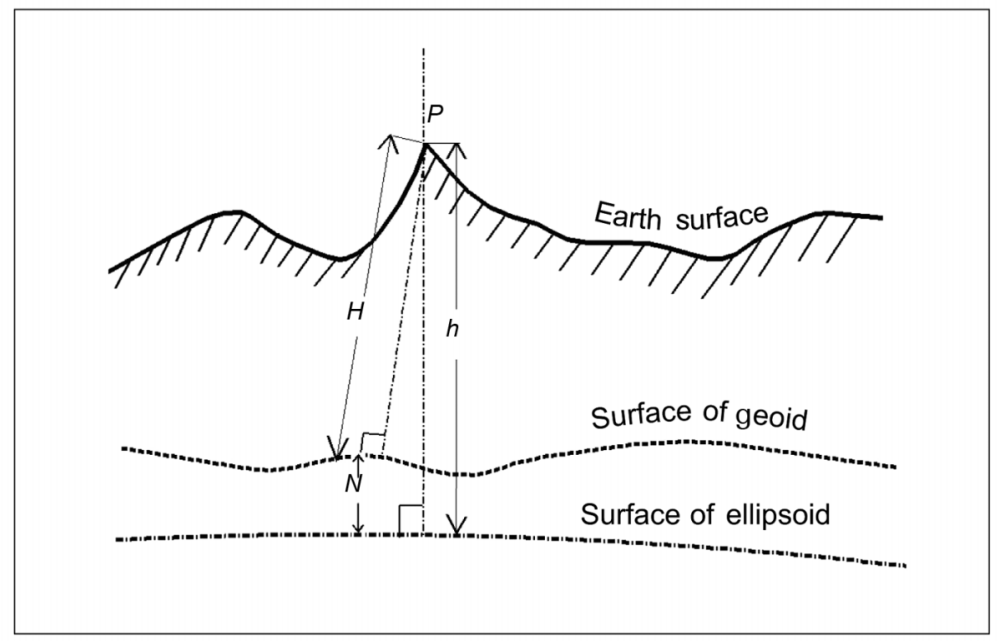

Fig. 1. The relationship between orthometric, geoid and ellipsoidal heights.

the gravimetric data (Kiamehr and Sjoberg, 2005). In some areas more accurate DEM (produced by the authors from stereo SPOT images via digital photogremmetry techniques) was used.

The Geoid Model could be obtained by GPS/ leveling measurements (geometric method) (Duquesne et al., 1995; Fotopoulos, 2003), or the gravimetric method (Rapp, 1997; Featherstone et al., 2001). While the geometric method is not easy to implement due to the poor spatial coverage of geometric leveling lines (Lee and Mazera, 2000), the gravimetric method utilizes a better distribution of terrestrial gravity observations and a global geopotential model (Bottoni and Barzaghi, 1993; Amos and Featherstone, 2003). Moreover, the geoid is considered to be a reference for the Earth gravity field and/or represents the vertical datum that permits the study of the sea-level. The geometric relation between the geoid, ellipsoid and Earth surface is shown in fig. 1, where the separation between orthometric height $(H)$ and ellipsoidal height $(h)$ is known as the geoid undulation $(N)$ (Heiskanen and Moritz, 1967)

$$
N=h-H \text {. }
$$

The initial practical application of the geoid undulation $(N)$ in land surveying is to transform GPS- derived ellipsoidal heights $(h)$ to orthome- tric heights $(H)$, (Al-Bayari et al., 1996) providing a benefit of utilizing GPS measurements as an alternative of the precise leveling for many applications.

\section{Methodology used and Global Geopotential Model}

There are many procedures that may be used for geoid determination (Sideris and She, 1995; Barzaghi et al., 1996; Arabelos and Tscherning, 2002). However, in this work the GeoJordan model is determined by the remove-restore and Least-Squares Collocation (LSC) procedure, implemented in GRAVSOFT package (Tscherning, 1994). The remove-restore approach is utilized whenever the long and short wavelength components of the geoid are computed. The main steps are:

- Spherical harmonic expansion impact; the remove procedure is carried out by computing the long wavelength component as gravity anomalies from the Global Geopotential Model $\left(\Delta g_{M}\right)$, then subtracted from the raw gravity $(\Delta g)$. This step is done for the two GGM's OSUA91A and EGM96 for analysis purposes (GEOCOL program).

- Residual Terrain Model (RTM) impacts; the short wavelength geoid height is then comput- 
ed from the resulting residual anomalies ( $\left.\Delta g_{\text {RTM }}\right)$. The terrain correction program in GRAVSOFT package (TC program) was used to compute the effect of topography from the Digital Terrain Model (DTM). The DTM is handled by analytical prism integration assuming a constant density of all masses above sea-level. After that the long wavelength component is restored as a geoid height computed from the GGM.

- The final step is to add the two components, short and long wavelength, producing a geoid height model. LSC is used to estimate the geoid heights and their errors (GEOCOL program).

In the remove-restore procedure the undulation $(N)$ is split into three components

$$
N=N_{M}+N_{\mathrm{RTM}}+N_{r} .
$$

Where $N_{M}$ represents the contribution from the GGM, $N_{\text {RTM }}$ the residual terrain effect contribution and $N_{r}$ the residual anomaly filed $\left(\Delta g_{r}\right)$, after removal of the contribution of GGM and terrain effect or the contribution of residual gravity anomalies

$$
\Delta g_{r}=\Delta g-\Delta g_{M}-\Delta g_{\mathrm{RTM}}
$$

\subsection{Global Geopotential Models}

Usually, the Global Geopotential Model (GGM) is computed as a series of spherical harmonic expansions to a maximum degree and sort comprises that describe the long-wavelength characteristics of the Earth's gravity field. OSU91A (Rapp et al., 1991) and EGM96 (Lemoine et al., 1998) are the most common global geopotential models applied for the Geoid Model computations. However, these models are completed up to degree and order 360 gravity anomalies and can be computed in spherical approximation from the geopotential coefficients (Rapp, 1997)

$$
\begin{aligned}
& \Delta g_{M}=\frac{\mathrm{GM}}{r^{2}} \sum_{n=2}^{M}\left(\frac{a}{r}\right)^{n}(n-1) \sum_{m=0}^{n}\left(\delta \bar{C}_{n m} \cos m \lambda+\right. \\
& \left.+\bar{S}_{n m} \sin m \lambda\right) \bar{P}_{n m}(\cos \theta)
\end{aligned}
$$

and the geoid height is computed from applying the GGM

$$
\begin{aligned}
& N_{M}=\frac{\mathrm{GM}}{r \gamma} \sum_{n=2}^{M}\left(\frac{a}{r}\right)^{n} \sum_{m=0}^{n}\left(\delta \bar{C}_{n m} \cos m \lambda+\bar{S}_{n m} \sin m \lambda\right) . \\
& \cdot \bar{P}_{n m}(\cos \theta)
\end{aligned}
$$

whereas GM is the product of the Newtonian gravitational constant and mass of the Earth, $\gamma$ is normal gravity on the surface of the reference ellipsoid, $(r, \theta, \lambda)$ are the geocentric spherical polar coordinates of the point at which $\Delta g$ is to be determined; $a$ is the semi-major axis of the geocentric reference ellipsoid; $\delta \bar{C}_{n m}$ and $\bar{S}_{n m}$ are the fully normalized spherical geopotential coefficients of the GGM, reduced; $\bar{P}_{n m}$ are the fully normalized associated Legendre functions for degree $n$ and order $m$; and $M$ is the maximum degree of spherical harmonic expansion.

OSU91A GGM model does not have enough data from the Middle East, but the EGM96 model contains some data from the Middle East. Therefore we took the EGM96 as the base model to represent the final results in this study. Also we have to consider that the data used to realize the EGM96 is highly compatible with new reference systems, such as ITRF.

\section{Data used for Gravimetric Jordanian Geoid Model}

Jordan extends between latitudes $29^{\circ}$ to $33^{\circ}$ and longitudes $35^{\circ}$ to $39^{\circ}$ and the area of Jordan is $87000 \mathrm{~km}^{2}$. The Gravimetric Jordanian Geoid Model uses a combination of three input data sources:

- Gravity data are collected by the NRAJ mainly for geophysical purposes; distributed over the whole country (about 3000 free-air gravity anomalies), they allow to determine the effect of the intermediate geoid wave length, around 5 to $10 \mathrm{~km}$. These data are part of the database covering the Jordan territory and are referenced to IGSN71. The distribution of the gravity data used is shown in fig. 2, the distance between points is approximately $5 \mathrm{~km}$, and the standard error declared by NRAJ is 2 mgal.

- Global Geopotential Model (GGM) to determine the long wave length of geoid undulations more than $100 \mathrm{~km}$. 
- Digital Elevation Model (DEM) which supplies most of the short wavelengths $(\sim 100 \mathrm{~m})$ and is also required to satisfy theoretical demands of geoid computation from the geodetic boundary-value problem. The resolution of SRTM used is $3^{\prime \prime} \times 3^{\prime \prime}$ pixel size and extended between $29^{\circ} \leq$ $\leq \varphi \leq 33^{\circ}$ and $35^{\circ} \leq \lambda \leq 39^{\circ}$. The SRTM DEM is edited using Terrascan and Terramodel programs (modules working under Microstation softwareBentley). Furthermore, the DEM shows good agreement with the topographic maps (differences less than $20 \mathrm{~m}$ ). The DEM used in the study area was $20 \mathrm{~m}$ pixel size and is produced using PCI-Geomatica software using SPOT-5 images; the standard error obtained of this DEM is less than $10 \mathrm{~m}$.

Since the normal gravity was evaluated on the surface of the GRS80 ellipsoid at the geocentric latitude of the gravity observation using Somigliana's closed formula (Moritz, 1980), therefore, the effect of vertical datum should be considered due to different reference surfaces used in rawdata; and to be aware of the transformation of GPS height to the local vertical datum. It is important to point out that all coordinate transformation from the national coordinate system to the geocentric datum was performed by applying a locally developed program.

Thus, the raw-data has been checked in the preprocessing step via various interpolation routines to isolate and eliminate error points. Error points elimination is very important because the errors will directly propagate into the created Geoid Model (Tscherning, 1991). Then, about 100 gravity data were considered to be outliers during preprocessing.

\section{GPS/leveling measurements}

The GPS/leveling measurements were carried out to study the accuracy of the Gravimetric Geoid Model (GeoJordan) (Kotsakis and Sideris, 1999). Two GPS observation techniques was used: the static and the rapid static techniques. The GPS static measurements were used to establish the reference network in the tested area using Leica SR530 GPS dual frequency receivers. The data were processed using Bernese 4.2 software and the static points were used as reference for

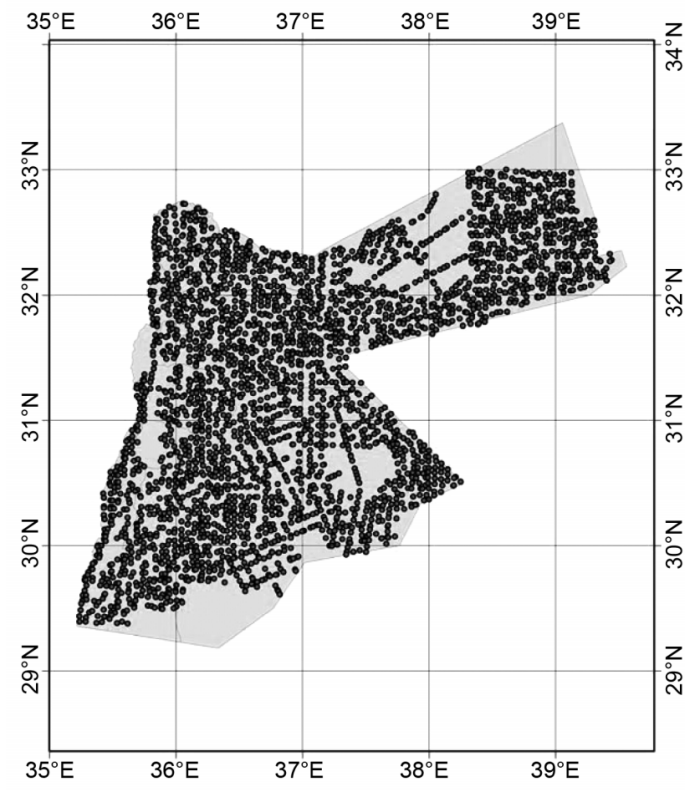

Fig. 2. Gravity data distribution over Jordan territory (latitude and longitude in WGS84).

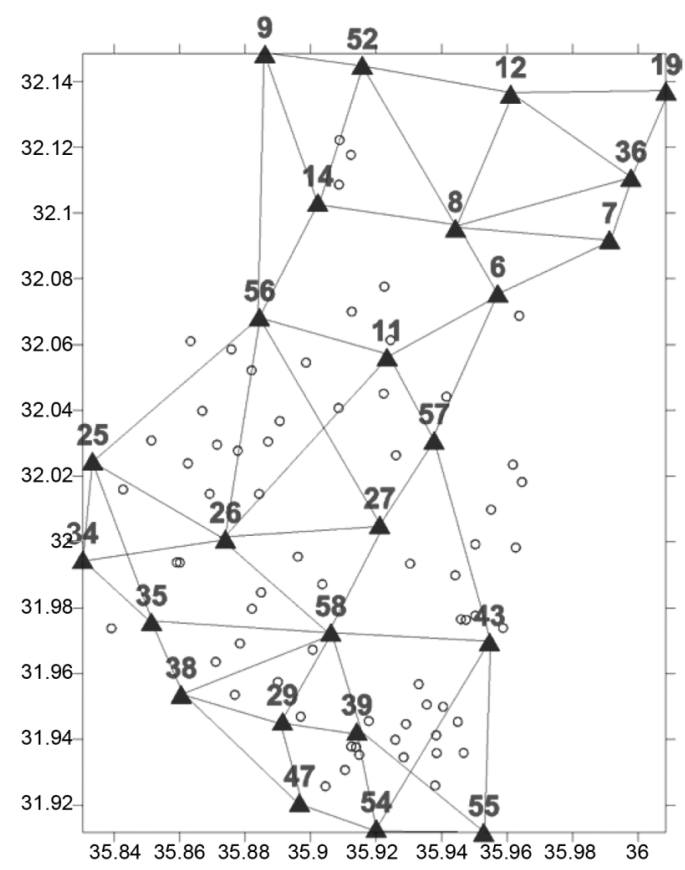

Fig. 3. GPS Static reference points and rapid static points (latitude and longitude in WGS84). 
rapid static survey. The rapid static and leveling measurements were used for the determination of geoidal undulation in the vicinity of Spirit leveling network in the study area (fig. 3). SKI-Pro software was used for GPS data processing and the accuracy obtained is within $3 \mathrm{~cm}$, considering that the baselines lengths are restricted to $5 \mathrm{~km}$. Spirit leveling network in Jordan is determined with respect to the mean sea-level defined at Aqaba Gulf.

\section{Results}

Actual computation of GeoJordan was done in accordance with the GRAVSOFT program using GGM models OSU91A and EGM96; accordingly the results are shown in fig. 4, and any error associated with this model is presented in fig. 5 where the standard error in flat areas is $0.2 \mathrm{~m}$ and reaches to $1 \mathrm{~m}$ in mountainous areas. However, this error resulted from the lack of gravity data particularly at the mountainous areas.

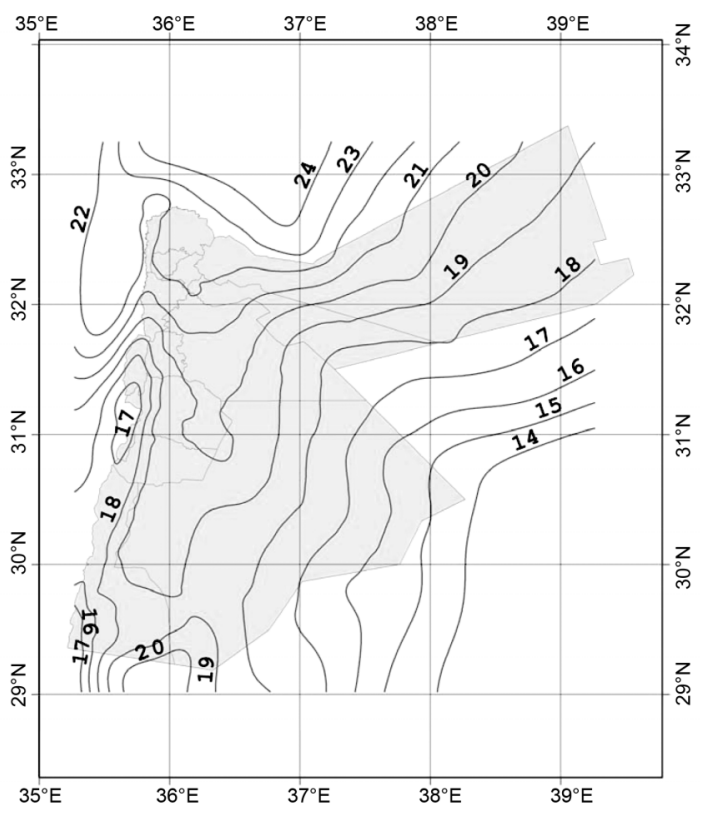

Fig. 4. The Gravimetric Jordanian-Geoid-Model «GeoJordan» (latitude and longitude in WGS84 and geoidal undulation in $\mathrm{m}$ ).

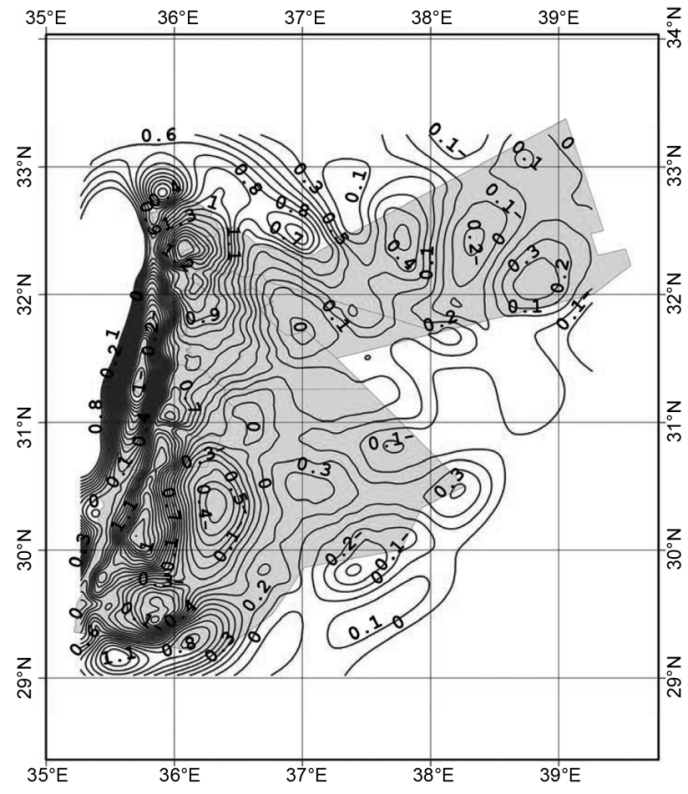

Fig. 5. The standard error associated with the «GeoJordan» (latitude and longitude in WGS84 and errors are expressed in $\mathrm{m}$ ).

Table I. Statistical parameters for the gravity residual $\left(\Delta g_{r}\right)$ computed using EGM96 and using OSU91A.

\begin{tabular}{lcc}
\hline \hline Statistical parameters & $\begin{array}{c}\text { OSU91A } \\
(\mathrm{mGal})\end{array}$ & $\begin{array}{c}\text { EGM96 } \\
(\mathrm{mGal})\end{array}$ \\
\hline No. of points & 2994 & 2994 \\
Average & -5.91 & -2.52 \\
Min & -211.33 & -162.82 \\
Max & 102.60 & 86.39 \\
Standard deviation & 31.82 & 28.44 \\
\hline
\end{tabular}

Statistical analysis of the gravity residual $\left(\Delta g_{r}\right)$ computed using EGM96 (table I) shows better behavior than those computed using OSU91A, and the differences range from 1 to 2 m (fig. 6). Then, the EGM96 is more accurate than the OSU91A due to the lack of gravity data of the Middle East area within the OSU91A model and to the long wavelength error propagation in the GGM. 


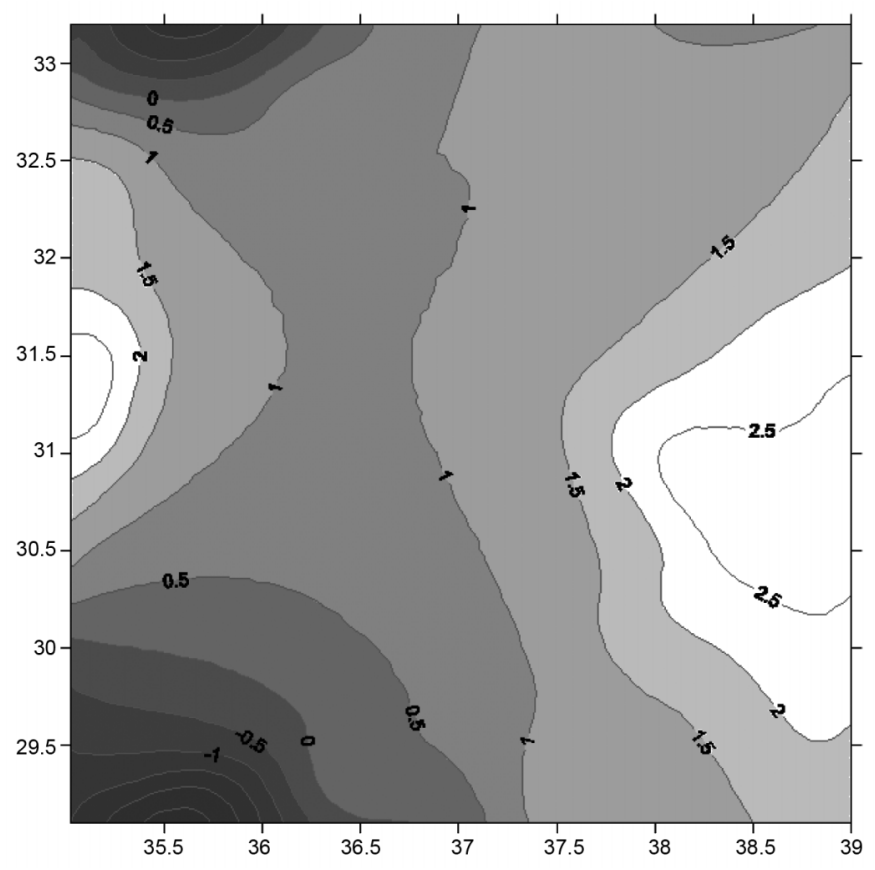

Fig. 6. The differences in meters, between the two models created in Jordan using OSU91A and EGM9 (latitude and longitude in WGS84).

\section{Model validation and discussion}

The experimental Geoidal undulation was calculated via a high quality GPS baseline, which is a promising approach in a local area due to its reliability, accuracy and even cost/ benefit ratio, especially for engineering and hydraulic applications. Meanwhile the experimental Geoidal surface and contour maps were created by interpolating the undulation values in a specific study area (in Amman city) to compare the experimental model with our resulting GeoJordan model.

In a first attempt: the experimental undulation in the tested area was compared with GeoJordan created from gravity data and the GGM OSU91A. However, as expected the agreement between GPS derived data and this model were not high-quality in the tested area.

In a second attempt: the GPS derived geoid was compared to the GeoJordan model created with GGM EGM96. At the points of GPS meas- urements, the nominal resulting accuracy was at decimeter level, these values were deducted by interpolating the model by means of weighted average technique (Yanalak and Baykal, 2001). Thus the point differences between the GPS undulation and the GeoJordan model showed a systematic behavior in some zones (fig. 7). However, the short wavelength differences may have resulted from the following errors: error in GPS/ leveling data, or due to localized errors in the gravity or terrain data. The topographic effect within the tested area could be the main factor for these differences (fig. 8). To model this systematic behavior and to decrease the impact of the vertical datum shift, a best-fit regression plane and multiquadric interpolation were used, where GPS data are assumed as reference $(x, y$, and $N)$. Therefore, both regression and multiquadric are subtracted from the GeoJordan undulation (fig. 9).

The mathematical models for regression plane and multiquadric interpolation are reported in (Yanalak and Baykal, 2001) 


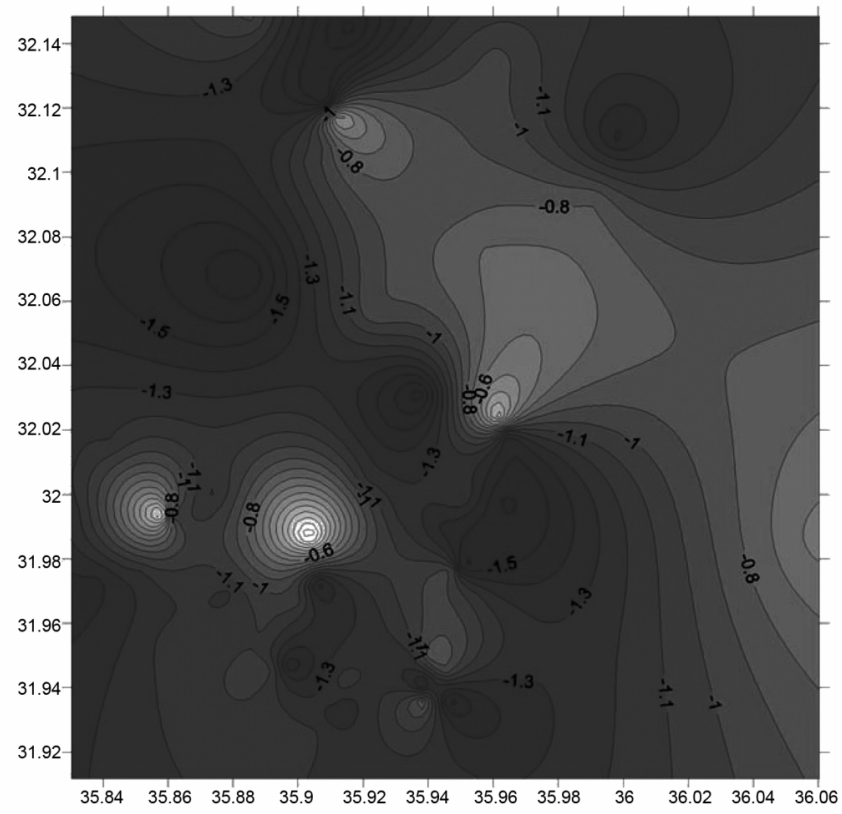

Fig. 7. Differences in meters, between Experimental Undulation (GPS/Levelling data) and gravimetric Jordananian Geoid Model (GeoJordan) before fitting (latitude and longitude in WGS84).

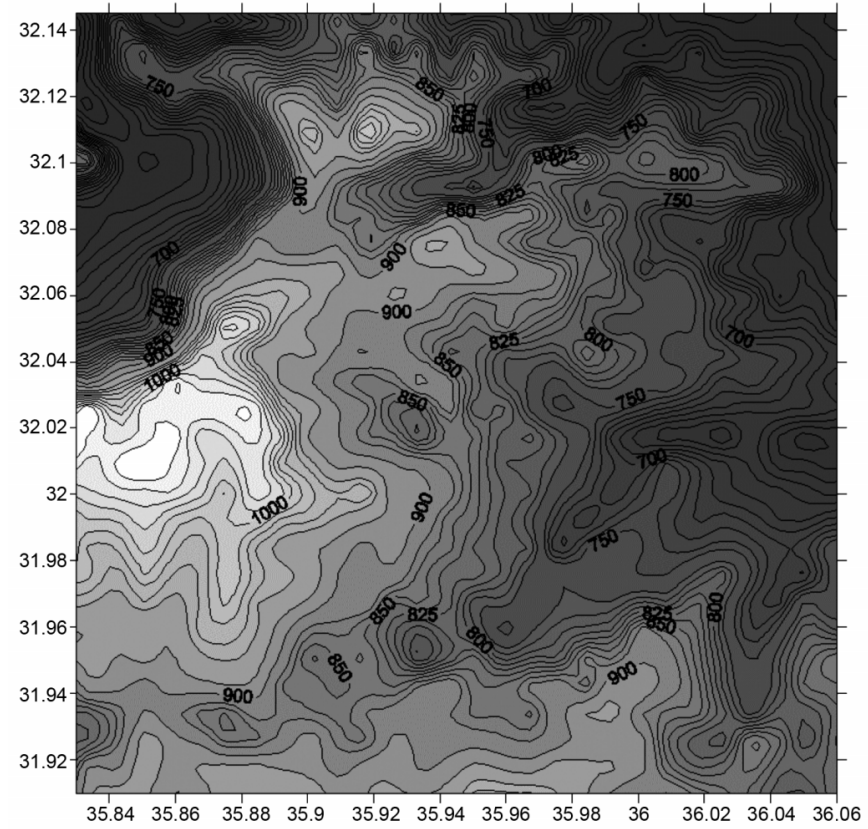

Fig. 8. The DTM extracted from the topographic map in tested area (latitude and longitude in WGS84 and contours value in meters). 


$$
\begin{aligned}
& N_{\text {exp }}-N_{\text {JordanGeo }}=a_{00}+a_{10} \cdot x+a_{01} \cdot y \\
& z\left(x_{0}, y_{0}\right)=a_{00}+a_{01} \cdot y_{0}+a_{10} \cdot x_{0}+a_{02} \cdot\left(x_{0}\right)^{2}+ \\
& +a_{11} \cdot x_{0} \cdot y_{0}+a_{02} \cdot\left(y_{0}\right)^{2} \\
& N_{\text {exp }}-N_{\text {JordanGeo }}=z\left(x_{0}, y_{0}\right)+\sum_{j=1}^{m} c_{j}\left[\left(x_{j}-x_{0}\right)^{2}+\right. \\
& \left.+\left(y_{j}-y_{0}\right)^{2}\right]^{0.5} \\
& \Delta z_{j}=\left(N_{\exp }-N_{\text {JordanGeo }}\right)-z\left(x_{0}, y_{0}\right) .
\end{aligned}
$$

Where $\left(a_{00} \ldots a_{02}\right)$ are the coefficient of the polynomial function that articulate the surface; in multiquadric interpolation $c_{j}$ is the unknown to be determined using the residuals $\Delta z_{j}$ at known reference points $\left(x_{j}, y_{j}\right)$. The least square method is used for the coefficient determination.

Naturally, the reference points should have a homogeneous distribution on the study area and should be available for interpolation of most of the remaining points. The method to fit the geoid's model with the experimental undulation is implemented in the $\mathrm{C}++$ program. The program is also used to transform the ellipsoidal height into orthometric height with their errors as reported in (Yanalak and Baykal, 2001).

The statistical results of the comparison are presented in table II, and the differences between the GeoJordan model and the experimental undulation after the application of the fitting procedure are presented in fig. 9. Since little information on the quality of leveling data and the vertical datum used in Jordan are available, the fitting method will minimize the effect of datum shift between the gravimetric model and geometric model. Table II shows that the multiquadric fitting has better behavior than regression plane due to irregular topography in the study area (fig. 8). This will be noticed when the tested area is extended in the near future using GPS/leveling measurements. The discrepancies appearing in fig. 7 (mainly due to the topography at the study area (fig. 8), force us to improve the model by includ-

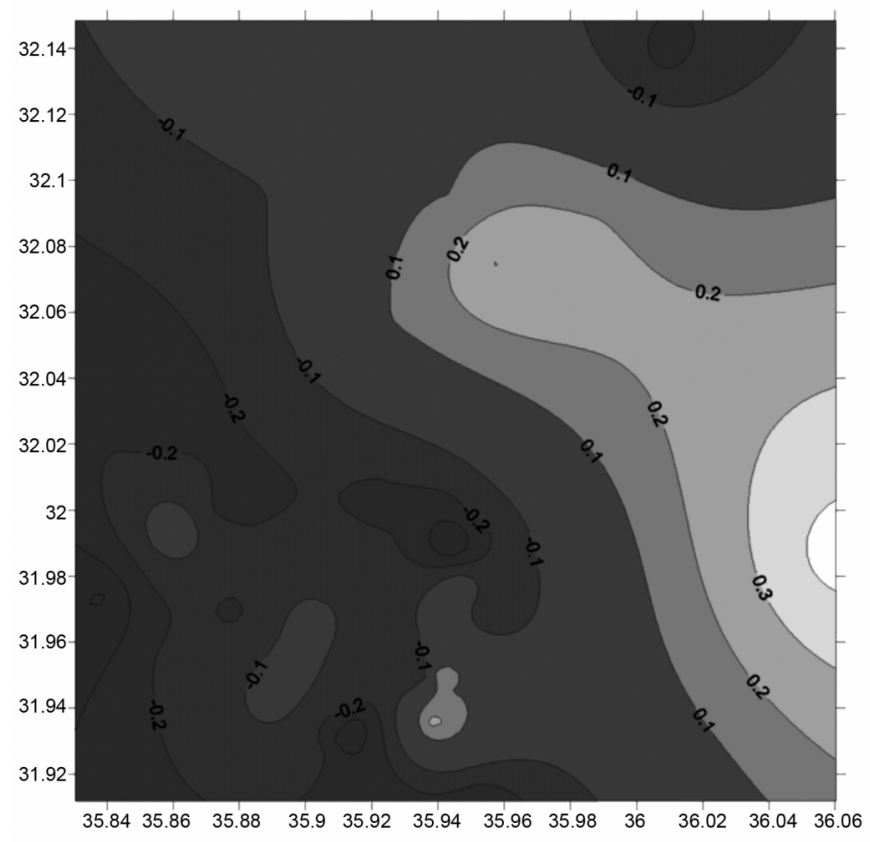

Fig. 9. Differences in meters, between Experimental Undulation (GPS/Leveling data) and gravimetric Jordanian Geoid Model (GeoJordan) after fitting (latitude and longitude in WGS84). 
Table II. Statistical parameters for the differences between WGS84 and GeoJordan Model (corrected by a regression plane and multiquadric).

\begin{tabular}{cccc}
\hline \hline \multicolumn{4}{c}{ Amman area (tested area) } \\
\hline $\begin{array}{c}\text { Statistical parameters } \\
\text { for the difference between } \\
\text { WGS84 and GeoJordan Model }\end{array}$ & $\begin{array}{c}\text { GPS/Leveling measurements } \\
\text { and GeoJordan }\end{array}$ & $\begin{array}{c}\text { The GeoJordan } \\
\text { (corr. by regression) } \\
(\mathrm{m})\end{array}$ & $\begin{array}{c}\text { The GeoJordan } \\
\text { (corr. by multiquadric) } \\
(\mathrm{m})\end{array}$ \\
\hline Average & -1.15 & -0.11 & 0.01 \\
Min & -1.85 & -0.43 & -0.37 \\
Max & 0.25 & 0.45 & 0.24 \\
Standard deviation & 0.41 & 0.19 & 0.16 \\
\hline
\end{tabular}

ing more gravity data and/or GPS/leveling data in the LSC procedure to create a centimeter Geoid Model. Consequently the fitting model shown in fig. 9 will not satisfy all the GPS users to obtain a reliable orthometric height at centimeter level from GPS measurements.

The second attempt results (table II and fig. 9) showed good correlation between GPS derived geoids and GeoJordan. This confirms the reliability and the high potential of GPS measurements combined with spirt leveling to adjust the «GeoJordan» particularly in irregular and mountainous areas.

\section{Conclusions}

A preliminary result of the Jordanian Gravimetric Geoid Model the «GeoJordan» is presented in this paper.

The model was validated through a comparison with a measured GPS/leveling data at Amman area and showed fairly good results.

The comparison also showed a high frequency problem in the estimation of GeoJordan, consequently this model needs more effort and time to be more accurate. The database should also be improved and extended to improve accuracy. This improvement includes: increasing the number and density of points (new GPS surveys are currently underway), combining the datasets with gravimetric data and definition of the vertical datum used in Jordan for orthometric height. This will be a great advantage in the analysis of results.
Due to the lack of access to the gravimetric data in the neighboring countries the border effect is clearly shown in the created model. To overcome this problem in the near future a regional model could be used instead of the global model, or the existing gravity data be combined with long-wave spectral components of the global model using a least squares spectral combination. This could be done by collaboration with national and international centers, such as International Geoid Service (IGeS).

This work also showed that the multiquadric and regression plane interpolation methods could be used for a local height transformation problem of GPS at the level of decimeter accuracy for a region with an area of about $40-50 \mathrm{~km}^{2}$.

Finally, the multiquadric interpolation gives a good level of accuracy in the extrapolation process, particularly in the irregular topographic areas.

\section{REFERENCES}

Al-Bayari, O., G. Bitelli, A. Capra, D. Donimici, E. ERColani, G. Folloni, S. Gandolfi, A. Pellegrinelli, M. Unguendoli and L. VitTuARI (1996): A local geoid in the South-East of the Po Valley, in Proceedings of the XXI Assembly European Geophysical Society, 6-10 May 1996, The Hague, The Netherlands, Session G-7 'Techniques for local geoid determination', 157-163.

Al-Zoubi, A.S. (2002): The Dead Sea Basin, its structural setting and evaporite tectonics, plate boundary zones, Geodyn. Ser. 30, 10.1029/030GD09, 145-172.

Amos, M.J. and W.E. Featherstone (2003): Progress towards a gravimetric geoid for New Zealand and a single national vertical datum, in Proceedings of the 3rd Meeting of the International Gravity and Geoid Commission, 
Gravity and Geoid 2002-GG2002, Thessaloniki, Greece, 395-400.

Arabelos, D. and C.C. Tscherning (2003): Globally covering apriori regional gravity covariance models, $A d v$. Geosci., 1, 143-147.

Barzaghi, R., M.A. Brovelli, A. Manzino, D. Sguerso and G. SonA (1996): The new Italian quasi-geoid ITALGEO95, Boll. Geod. Sci. Affini, 15 (1), 57-72.

BotToni, G.P. and R. BARZAGHI (1993): Fast collocation, Bull. Geod., 67, 119-126.

DuQuenNe, H., Z. JiAnG and C. LEMARIE (1995): Geoid determination and levelling by GPS: some experiments on a test network, in Proceedings of the IAG Symposium, 1994, Graz, Austria, 559-568.

Featherstone, W.E., M.S. DENITH and J.F. Kirby (1998): Strategies for the accurate determination of Orthometric Heights, Surv. Rev., 34 (267), 278-296.

Featherstone, W.E., J.F. Kirby, A.H.W Kearsley, J.R Gilliland, G.M. Johnston, J. SteEd, R. Forsberg and M.G. SIDERIS (2001): The AUSGeoid98 Geoid Model of Australia: data treatment, computations and comparisons with GPS-levelling data, J. Geod., 75, 313-330.

Fotopoulos, G. (2003): An analysis on the optimal combination of Geoid, orthometric and ellipsoidal height data, Ph.D. Thesis (University of Calgary, Department of Geomatics Engineering, Canada).

Heiskanen, W.A. and H. Moritz (1967): Physical Geodesy (W.H. Freeman and Company San Francisco), pp. 370.

KIAMEHR, R. and L.E. SJobERG (2005): Effect of the SRTM global DEM in the determination of a high-resolution Geoid Model of Iran, J. Geod., 79 (9), 540-551.

KotsAKIS, C. and M.G. SIDERIS (1999): On the adjustment of combined GPS/levelling/geoid networks, J. Geod., 73 (8), 412-421.

LEE, J.T. and D.F. MAZERA (2000): Concerns related to GPSderived Geoid determination, Surv. Rev., 35 (276), 379397.

Lemoine, F.G., S.C. Kenyon, R.G. FACtor, R.G. TRimmer,
N.K. Pavlis, D.S. Chinn, C.M. Cox, S.M. Klosko, S.B. Luthcke, M.H. Torrence, Y.M. Wang, R.G. Williamson, E.C. Pavlis, R.H. RaPP and T.R. Olson (1998): The development of the joint NASA GSFC and the National Imagery and Mapping Agency (NIMA) geopotential model EGM96, NASA/TP-1998-206861 (NASA, Washington), pp. 575.

MART, U. (2002): Modelling of different height systems in Switzerland, presented at the IAG Third Meeting of International Gravity and Geoid Commission, August 26-30, 2002, Thessaloniki, Greece.

Moritz, H. (1980): Geodetic reference system 1980, Bull. Geod., 54, 395-405.

RAPP, R.H. (1997): Use of the potential coefficient models for geoid undulation determinations using harmonic representation of the height anomaly/geoid undulation difference, J. Geod., 71 (5), 282-289.

RAPP, R.H., Y.M. WANG and N.K. PAVLIS (1991): The Ohio State 1991 geopotential and sea surface topography harmonic coefficient model, Report 410 (Department of Geodetic Science and Surveying, Ohio State University, Columbus).

SiderIS, M. and B. SHE (1995): A new, high-resolution geoid for Canada and part of the US by the 1D-FFT method, Bull. Geod., 69 (2), 92-108.

TsCHERNING, C.C. (1991): The use of optimal estimation for gross-error detection in databases of spatially correlated data, BGI, Bull. Inf., 68, 79-89.

TsCHERNING, C.C. (1994): Geoid determination by leastsquares collocation using GRAVSOFT, Lecture Notes of the International School for the Determination and Use of the Geoid (DIIAR - Politecnico di Milano, Milano).

YANALAK, M. and O. BAYKAL (2001): Transformation of ellipsoid heights to local leveling heights, J. Surv. Eng., 127 (3), 90-103.

(received January 19, 2007; accepted May 3, 2007) 